\title{
Nimodipine-refractory reversible cerebral vasoconstriction syndrome treated effectively with verapamil
}

\author{
So Young Park ${ }^{1}$, Joon Ho Lee ${ }^{1}$, In Ja Shin ${ }^{1}$, Raul G. Nogueira ${ }^{2,3}$, Jin Soo Lee ${ }^{1,2,3}$
}

${ }^{1}$ Department of Neurology, Ajou University Hospital, Ajou University School of Medicine, Suwon, Korea

${ }^{2}$ Department of Neurology and Radiology, Emory University, Atlanta, GA, USA

${ }^{3}$ Neuroendovascular Service, Grady Memorial Hospital, Atlanta, GA, USA

Received: November 30, 2020

Revised: December 10, 2020

Accepted: December 10, 2020

Corresponding author:

Jin Soo Lee

Department of Neurology, Ajou University Hospital, Ajou University School of Medicine, 164 World cup-ro, Yeongtonggu, Suwon 16499, Korea

Tel: +82-31-219-5175

E-mail: jinsoo22@gmail.com

\section{ABSTRACT}

Reversible cerebral vasoconstriction syndrome (RCVS) is characterized by recurrent thunderclap headache and reversible multifocal vasoconstrictions of the cerebral arteries. There are no treatment guidelines despite its potential for precarious outcomes. A 52-year-old woman with recurrent episodes of severe headache was diagnosed with RCVS and treated with oral nimodipine, which has been widely used for RCVS. However, her vessel status worsened despite treatment for several days and only improved after administration of intra-arterial (IA) and per os (PO) verapamil, which has been used to reverse vasoconstrictions in variant angina. Based on this case and literatures, we propose an alternative strategy using verapamil. The presence of a vascular reaction after an IA verapamil challenge during initial digital subtraction angiography can diagnose RCVS while also serving as an emergent treatment. Based on the response to IA verapamil, PO verapamil can be prescribed if there are no contraindications or side effects.

Keywords: Nimodipine; Reversible cerebral vasoconstriction syndrome; Verapamil
This is an Open Access article distributed under the terms of the Creative Commons Attribution Non-Commercial License (https:// creativecommons.org/licenses/ by-nc/4.0/).

\section{INTRODUCTION}

Reversible cerebral vasoconstriction syndrome (RCVS) is defined as a sudden onset of severe headache and multiple reversible segmental vasoconstrictions of the cerebral arteries with or without focal neurologic deficits [1]. When diagnosing RCVS, other intracranial angiopathies that manifest with a similar angiographic findings should be excluded; examples of such pathologies include primary angiitis of the central nervous system, aneurysmal subarachnoid hemorrhage $(\mathrm{SAH})$, moyamoya disease, and intracranial arterial dissection [1]. While there are no guidelines for the management of RCVS, nimodipine, which is used to treat vasospasm in $\mathrm{SAH}$, is widely used for RCVS.

We report a case of RCVS that did not respond to per os (PO) nimodipine or steroid administration. Temporary recovery was observed after administration of intra-arterial (IA) verapamil, but improvement was only achieved after replacing PO nimodipine with PO verapamil. 


\section{CASE REPORT}

This is a retrospective case study. Written informed consent by the following patient was waived due to a retrospective nature of our study.

A 52-year-old woman was referred to our hospital by a local clinic. She presented with recurrent episodes of severe thunderclap headache with 10 of a numeric rating scale score (maximum, 10) for the past 7 days accompanied by nausea and vomiting. Her headache lasted for about 2 hours after taking the pain reliever, then slightly improved, worsened again in 5 hours, and there was no significant exacerbation factor. Apart from dyslipidemia that was being treated with rosuvastatin, she had no other pertinent findings in her past medical history. The patient did not show any neurologic deficits on neurological examination, and there was no evidence of inflammation in cerebrospinal fluid (CSF) and serological testing. A brain magnetic resonance imaging with angiography was taken at the local clinic which documented multifocal stenoses on bilateral anterior cerebral arteries (ACAs) and M2 segments middle cerebral arteries (MCAs) without ischemic or hemorrhagic complications. Upon admission in our hospital, digital subtraction angiography (DSA) showed the same findings (Fig. 1). Treatment was started with $\mathrm{PO}$ nimodipine $60 \mathrm{mg}$ three times a day.

Computed tomography angiography (CTA) was performed on hospital day 9 and showed worsening of vasoconstriction in multiple areas despite the mild improvement of the patient's headache without focal neurologic symptom from hospital day 4. Repeat DSA revealed severe vasoconstriction in the bilateral ACAs and MCAs (Fig. 1). A total of $4 \mathrm{mg}$ of IA verapamil was slowly infused in both internal carotid arteries, after which the vessels normalized angiographically (Fig. 1). After the procedure, the PO nimodipine was still administered, and pain relievers that were helpful intermittently were stopped entirely. Favorably, her headache did not worsen until discharge. However, on day 11 , CTA revealed recurrent multifocal vasoconstrictions (Fig. 1). Although vasculitis serology tests were negative, $\mathrm{PO}$ glucocorticoids were empirically added for presumed inflammation. However, these treatments failed to resolve the vasoconstrictions (Fig. 1).

Based on the patient's responsiveness to IA verapamil, PO verapamil was administered and titrated to $240 \mathrm{mg}$ slow release form (SR) twice a day. While increasing verapamil gradually, the blood pressure decreased, but no significant hypotension was observed, and there were no other side effects.

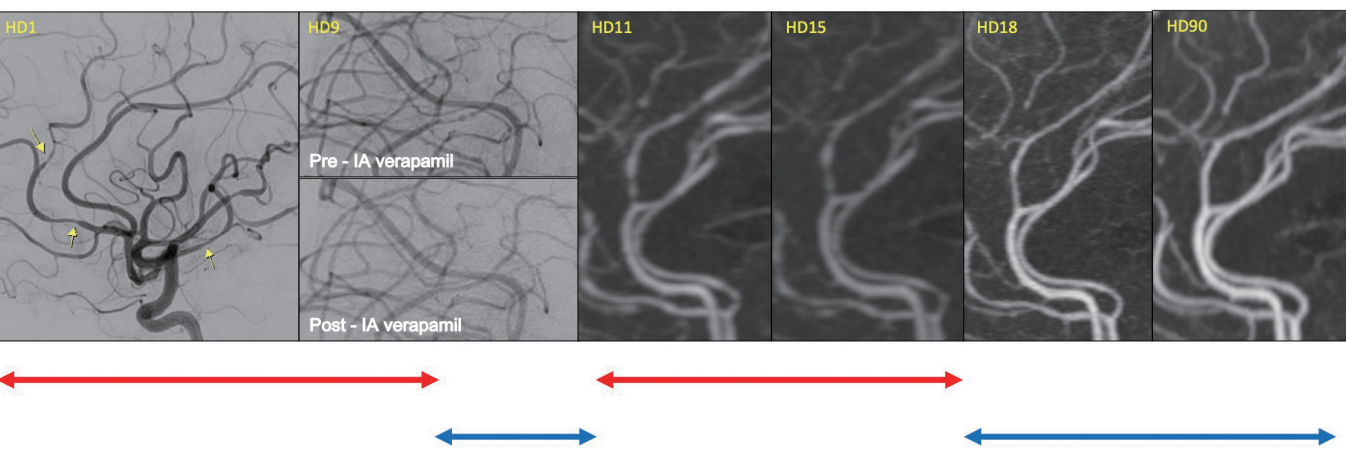

Vessel normalized

Nimodipine $180 \mathrm{mg}$ PO

IA verapamil $4 \mathrm{mg}$

Prednisolone $60 \mathrm{mg}$ PO

Verapamil $480 \mathrm{mg}$ PO

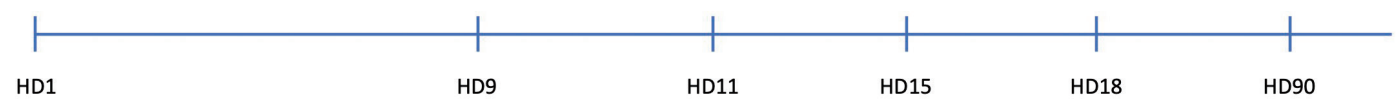

Fig. 1. Timeline of the order of drugs administered to the patient and changes in blood vessel conditions. On hospital day (HD) 1, initial digital subtraction angiography (DSA) showed multifocal stenoses on the M2 division of the right middle cerebral artery and the ipsilateral anterior cerebral artery. On HD 9, upon treatment with per os (PO) nimodipine, repeat DSA showed aggravated diffuse vasoconstrictions with "string of beads" appearance in middle cerebral artery branches which resolved following intra-arterial (IA) verapamil infusion. On HD 11 , vasoconstriction recurred 2 days after treatment with PO nimodipine. On HD 15, no definite interval changes in vascular status were noted. On HD 18, recovery of the diffuse vasoconstrictions was observed after PO verapamil was administered. On HD 90, the appearance of the cerebral arteries had returned to normal and verapamil was tapered and then discontinued. 


\section{PRECISION AND FUTURE MIEDICINE}

So Young Park, et al.

Nimodipine was discontinued and the PO glucocorticoid was tapered off for 4 days. Follow-up CTA showed a substantial improvement with only mild residual narrowing of several vessels (Fig. 1) and the patient was discharged. After 3 months, CTA showed complete normalization of the previous areas of stenosis, and PO verapamil was tapered and then discontinued. Repeat CTA 7 months after discharge showed normal findings.

\section{DISCUSSION}

RCVS is characterized by reversible segmental vasoconstriction of the cerebral arteries and subsequent dilation; this condition usually manifests as a thunderclap headache with or without neurologic symptoms [2]. The criteria required to diagnose RCVS are as follows: (1) normal or near-normal CSF analysis results, (2) documentation of multifocal segmental cerebral artery narrowing on DSA or CTA, (3) absence of evidence of aneurysmal SAH, and (4) reversibility of angiographic abnormalities within 12 weeks after onset [3]. Angiographic findings consistent with RCVS include several smooth or tapered stenosis of the medium and large arteries with normal or dilated arterial segments resulting in a "bead and string" or "sausage and string" appearance [4]. Most patients with RCVS have a benign clinical course. Approximately $80 \%$ of the patients have excellent clinical outcomes at short-term follow-up after 2 to 4 months [1]. However, some RCVS patients experience progressive vasoconstriction and disabling

Table 1. Comparison of nimodipine and verapamil $[14,17]$

\begin{tabular}{|c|c|c|}
\hline & Nimodipine & Verapamil \\
\hline Drug class & Dihydropyridine CCB & Non-dihydropyridine (phenylalkylamines) CCB \\
\hline \multirow[t]{3}{*}{ Generation of CCBs } & 2nd generation & 1st generation \\
\hline & - Slow release, longer acting & - A rapid onset and short duration of action \\
\hline & - Fewer vasodilatation-mediated adverse effects & - Adverse effects related to rapid arterial vasodilation \\
\hline Half-life & $8-9 \mathrm{hr}$ & $3-7 \mathrm{hr}$ \\
\hline \multirow[t]{2}{*}{ Distribution of receptors } & Vascular smooth muscle cells (cerebral >peripheral) & Vascular smooth muscle cells (coronary, cerebral) \\
\hline & & Conductible and contractile myocardial cells \\
\hline Vasodilatory mechanism & Block L-type voltage-gated calcium channels & Block L- and T-type voltage gated calcium channels \\
\hline \multirow[t]{4}{*}{ Approved indications } & Vasospasm following subarachnoid hemorrhage & Variant angina, angina pectoris \\
\hline & Migraine & Cluster headache \\
\hline & & Hypertension \\
\hline & & $\begin{array}{l}\text { Tachyarrhythmia (atrial fibrillation, atrial flutter, } \\
\text { supraventricular tachycardia) }\end{array}$ \\
\hline \multirow[t]{5}{*}{ Contraindications } & Severe hypotension & Severe hypotension \\
\hline & & Severe congestive heart failure \\
\hline & & Sick sinus syndrome \\
\hline & & Second- or third-degree atrioventricular block \\
\hline & & Atrial fibrillation with Wolff-Parkinson-White syndrome \\
\hline \multirow[t]{6}{*}{ Side effects } & Pruritus & Constipation \\
\hline & Gastrointestinal hemorrhage & Dizziness \\
\hline & Thrombocytopenia & Nausea \\
\hline & Vomiting & Low blood pressure \\
\hline & Diaphoresis & headache \\
\hline & Congestive heart failure & \\
\hline Extended-release formulation & No & Yes \\
\hline \multirow[t]{2}{*}{ Drug interaction } & Decreased by macrolides and antifungal agents & Decreased by rifampin, erythromycin \\
\hline & & Increased by colchicine, midazolam \\
\hline
\end{tabular}

CCB, calcium-channel blocker. 
stroke despite receiving calcium channel blockers (CCBs) or glucocorticoids $[1,5]$.

No randomized control trials for the management of RCVS have been conducted. However, it has been reported that the use of CCBs is associated with good outcomes; therefore, these drugs have been widely used as the first-line therapy in patients with RCVS [1]. Nimodipine is a dihydropyridine CCB that acts mainly on vascular smooth muscle. Nimodipine is lipophilic, crosses the blood-brain barrier and longer-acting compared to other CCBs $[6,7]$. Randomized controlled trials have shown that PO nimodipine can improve clinical outcomes in patients with cerebral vasospasm after SAH $[8,9]$. Furthermore, because of its selective affinity for cerebral arteries beyond the blood-brain barrier [10], nimodipine has been reported to shorten the clinical course of RCVS when administered early [11]; however, it has not been shown to confer any benefit regarding resolving vasoconstriction and preventing complications [11]. Even despite early nimodipine treatment, vasoconstriction can be worsened and later improved, apart from improving clinical symptoms [12]. In our case, nimodipine could only provide symptomatic relief by reducing the severity and frequency of headaches; it did not help resolve the patient's multifocal stenosis and even aggravated the vessel status. There have been previous literature that cerebral vascular focal stenosis in RCVS patients is associated with the occurrence of complications such as ischemic stroke [12]. Therefore, we have considered other therapeutic options that can be expected to improve vasoconstriction.

Verapamil is widely used to treat variant angina secondary to coronary vasospasm and has been reported to improve vasospasm without hypertensive intracranial complications [13]. The pathophysiology of variant angina is similar to that of RCVS in that both exhibit reversible arterial vasoconstric-

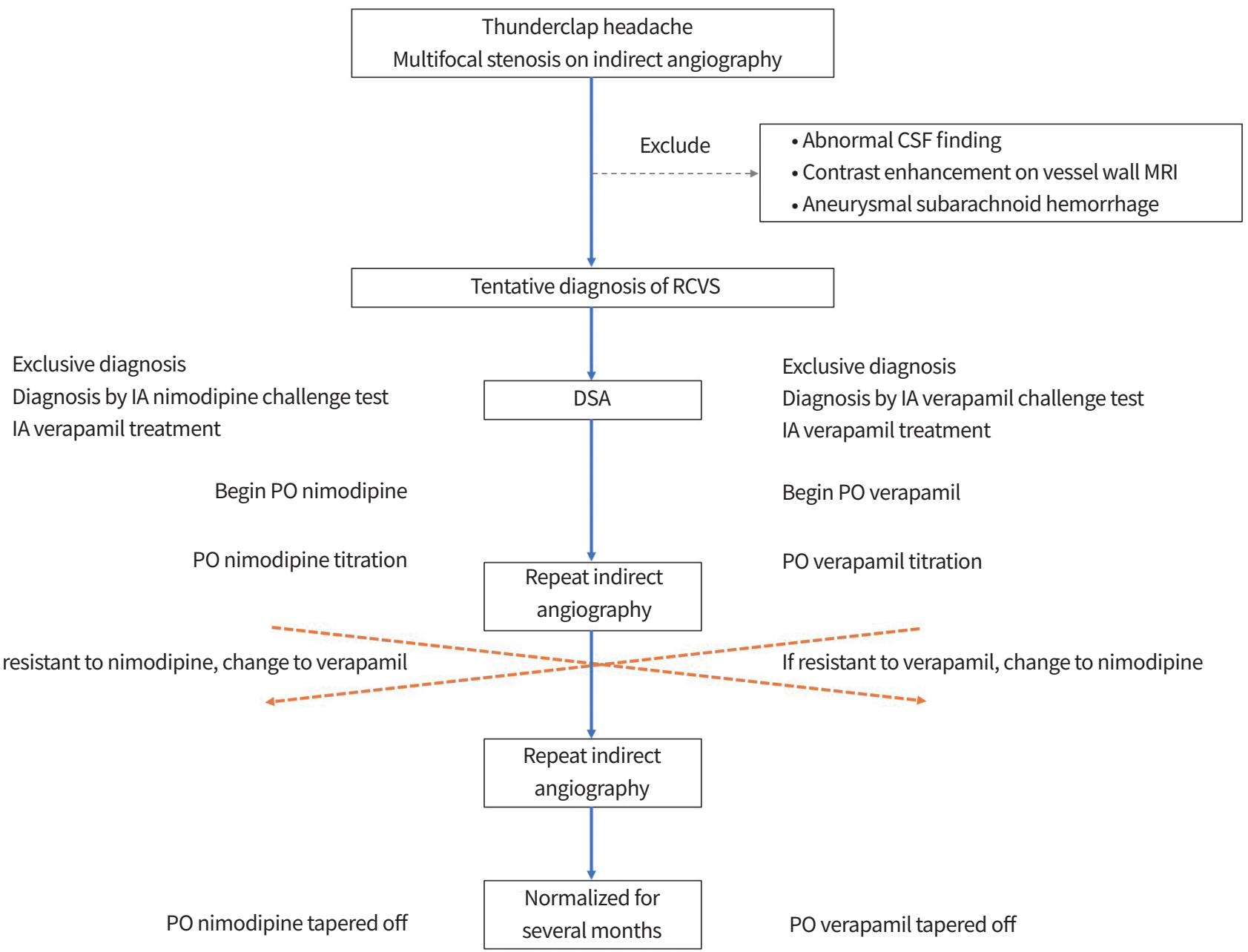

Fig. 2. Proposal of a novel strategy for reversible cerebral vasoconstriction syndrome (RCVS) diagnosis and treatment. CSF, cerebrospinal fluid; MRI, magnetic resonance imaging; IA, intra-arterial; PO, per os; DSA, digital subtraction angiography. 
tion. Verapamil is a phenylalkylamine (non-dihydropyridine) CCB with a half-life shorter than nimodipine (Table 1) that acts on the smooth muscles of the cerebral arteries, which are structurally similar to the coronary arteries [14]. Although experiments have demonstrated a short duration of effect, it has been suggested that verapamil is amphiphilic and has a wide distribution in the brain, thereby allowing it to persist in the patient's body [15]. While nimodipine has a relatively longer duration of effect compared to verapamil, the effects of both drugs disappear within 2 hours [14]. Therefore, it is important to ensure that a drug's duration of effect will persist after the intervention is given. As for PO administration, a study reported that administration of slow-releasing verapamil was more effective than nimodipine in patients with RCVS [16]. Characteristics between nimodipine and verapamil are compared in Table $1[14,17]$.

IA administration of verapamil in patients with refractory and progressive RCVS was suggested as another effective therapeutic option $[18,19]$. In contrast to PO or intravenous administration, this targeted approach reduces the possibility of persistent systemic hypotension, thus avoiding concerns about the occurrence of infarction in vascular border zones [19]. IA administration of verapamil is suggested to be both, a diagnostic tool and therapeutic option for patients with severe refractory RCVS. Recent studies have reported that vascular changes after administration of IA verapamil or other vasodilators such as nicardipine or milrinone can aid in diagnosing RCVS [20,21].

In summary, we report the case of a patient diagnosed with RCVS who experienced worsening vasoconstriction despite treatment with PO nimodipine and glucocorticoids. While vascular recovery was observed after IA administration of verapamil, multifocal stenoses reformed during the PO nimodipine treatment. The patient's vessel status normalized after replacing PO nimodipine with PO verapamil. Based on this case, we propose a bridging treatment for RCVS composed of emergent DSA and IA verapamil challenges and PO verapamil titration as an alternative of nimodipine (Fig. 2). Larger prospective studies are warranted to verify the appropriate dose for treatment and the efficacy and safety of these methods.

\section{CONFLICTS OF INTEREST}

No potential conflict of interest relevant to this article was reported.

\section{ORCID}

So Young Park https://orcid.org/0000-0002-8625-6968

Joon Ho Lee https://orcid.org/0000-0002-6637-1352

In JaShin https://orcid.org/0000-0002-7260-1409

Raul G. Nogueira https://orcid.org/0000-0003-4532-153X

Jin Soo Lee https://orcid.org/0000-0002-7225-6166

\section{AUTHOR CONTRIBUTIONS}

Conception or design: SYP, JSL.

Acquisition, analysis, or interpretation of data: SYP, JSL.

Drafting the work or revising: SYP, RGN, JSL.

Final approval of the manuscript: SYP, JHL, IJS, RGN, JSL.

\section{REFERENCES}

1. Singhal AB, Hajj-Ali RA, Topcuoglu MA, Fok J, Bena J, Yang $D$, et al. Reversible cerebral vasoconstriction syndromes: analysis of 139 cases. Arch Neurol 2011;68:1005-12.

2. Ducros A. Reversible cerebral vasoconstriction syndrome. Lancet Neurol 2012;11:906-17.

3. Calabrese LH, Dodick DW, Schwedt TJ, Singhal AB. Narrative review: reversible cerebral vasoconstriction syndromes. Ann Intern Med 2007;146:34-44.

4. Ducros A, Boukobza M, Porcher R, Sarov M, Valade D, Bousser MG. The clinical and radiological spectrum of reversible cerebral vasoconstriction syndrome. A prospective series of 67 patients. Brain 2007;130(Pt 12):3091-101.

5. Singhal AB, Topcuoglu MA. Glucocorticoid-associated worsening in reversible cerebral vasoconstriction syndrome. Neurology 2017;88:228-36.

6. Li YX, Liu AH, Lu M, Jiang CH, Zhang YP, Yang XJ, et al. Endovascular treatment of posterior cerebral artery aneurysm: analysis of 21 patients. Zhonghua Yi Xue Za Zhi 2006;86:2033-6.

7. Tallarico RT, Pizzi MA, Freeman WD. Investigational drugs for vasospasm after subarachnoid hemorrhage. Expert Opin Investig Drugs 2018;27:313-24.

8. Petruk KC, West M, Mohr G, Weir BK, Benoit BG, Gentili F, et al. Nimodipine treatment in poor-grade aneurysm patients. Results of a multicenter double-blind placebo-controlled trial. J Neurosurg 1988;68:505-17.

9. Connolly ES Jr, Rabinstein AA, Carhuapoma JR, Derdeyn $\mathrm{CP}$, Dion J, Higashida RT, et al. Guidelines for the management of aneurysmal subarachnoid hemorrhage: a guideline for healthcare professionals from the American 
PRECISION AND FUTURE MIEDICINE

Reversible cerebral vasoconstriction syndrome

Heart Association/American Stroke Association. Stroke 2012;43:1711-37.

10. Shimoyama T, Uchino K, Hajj-Ali RA. Reversible cerebral vasoconstriction syndrome: an update of recent research. Curr Treatm Opt Rheumatol 2020;6:55-70.

11. Cho S, Lee MJ, Chung CS. Effect of nimodipine treatment on the clinical course of reversible cerebral vasoconstriction syndrome. Front Neurol 2019;10:644.

12. Chen SP, Fuh JL, Wang SJ, Chang FC, Lirng JF, Fang YC, et al. Magnetic resonance angiography in reversible cerebral vasoconstriction syndromes. Ann Neurol 2010;67: 648-56.

13. Taniyama Y, Ito H, Iwakura K, Masuyama T, Hori M, Takiuchi S, et al. Beneficial effect of intracoronary verapamil on microvascular and myocardial salvage in patients with acute myocardial infarction. J Am Coll Cardiol 1997; 30:1193-9.

14. Lim J, Cho YD, Kwon HJ, Byoun SH, Koh HS, Park B, et al. Duration of vasodilatory action after intra-arterial infusions of calcium channel blockers in animal model of cerebral vasospasm. Neurocrit Care. 2020 Sep 25 [Epub]. https://doi.org/10.1007/s12028-020-01112-0.

15. Feng L, Fitzsimmons BF, Young WL, Berman MF, Lin E, Aagaard BD, et al. Intraarterially administered verapamil as adjunct therapy for cerebral vasospasm: safety and 2-year experience. AJNR Am J Neuroradiol 2002;23:1284-
90.

16. Marsh EB, Ziai WC, Llinas RH. The need for a rational approach to vasoconstrictive syndromes: transcranial doppler and calcium channel blockade in reversible cerebral vasoconstriction syndrome. Case Rep Neurol 2016;8:16171.

17. Godfraind T. Discovery and development of calcium channel blockers. Front Pharmacol 2017;8:286.

18. Farid H, Tatum JK, Wong C, Halbach W, Hetts SW. Reversible cerebral vasoconstriction syndrome: treatment with combined intra-arterial verapamil infusion and intracranial angioplasty. AJNR Am J Neuroradiol 2011;32:E184-7.

19. Ospel JM, Wright CH, Jung R, Vidal LLM, Manjila S, Singh $\mathrm{G}$, et al. Intra-arterial verapamil treatment in oral therapy-refractory reversible cerebral vasoconstriction syndrome. AJNR Am J Neuroradiol 2020;41:293-9.

20. Sequeiros JM, Roa JA, Sabotin RP, Dandapat S, Ortega-Gutierrez S, Leira EC, et al. Quantifying intra-arterial verapamil response as a diagnostic tool for reversible cerebral vasoconstriction syndrome. AJNR Am J Neuroradiol 2020;41:1869-75.

21. Kass-Hout T, Kass-Hout O, Sun CH, Kass-Hout T, Ramakrishnan $\mathrm{P}$, Nahab F, et al. A novel approach to diagnose reversible cerebral vasoconstriction syndrome: a case series. J Stroke Cerebrovasc Dis 2015;24:e31-7. 